\title{
Iron release from ferritin induced by light and ionizing radiation
}

\author{
Marian Wolszczak · Joanna Gajda
}

Received: 23 April 2010/Accepted: 15 June 2010/Published online: 17 August 2010

(C) The Author(s) 2010. This article is published with open access at Springerlink.com

\begin{abstract}
The reductive release of iron from ferritin by UV light or ionizing radiation has been investigated in separate experiments. When ferritin is exposed to light, the mineral core is the main photoreceptor for the $\mathrm{Fe}$ (III) reduction. In radiolytic studies, we determined that, in the absence of oxygen, the hydrated electron $\left(\mathrm{e}_{\mathrm{aq}}^{-}\right)$is the reducing agent triggering redox reactions associated with iron mobilization from ferritin. In an aerobic system, the superoxide radical anion $\left(\mathrm{O}_{2}^{\bullet-}\right)$ is also involved in the iron release process. We found that, in photochemical and radiolytical studies, Fe(II) mobilization from ferritin required an iron chelator. Without a chelator, ferritin is an electron-storage molecule for a long period, on the order of at least several hours. The reductant or chelator entry into the ferritin core is not necessary for iron release. The ferrozine is a convenient chelating agent to monitor Fe(II) mobilization, due to a high extinction coefficient of Fe (ferrozine) ${ }_{3}^{4-}$ and a high rate constant of complexation process $\left(2.65 \times 10^{4} \mathrm{dm}^{3} \mathrm{~mol}^{-1} \mathrm{~s}^{-1}\right)$.
\end{abstract}

Keywords Ferritin - Ferric mineral core - Laser flash photolysis ·

Pulse radiolysis

\section{Introduction}

Ferritin, the iron-storage protein found in many living organisms, including bacteria, insects, plants, invertebrates, and vertebrates, is unique in the sense that it performs

\footnotetext{
M. Wolszczak $(\bowtie)$

Institute of Applied Radiation Chemistry, Technical University, Wroblewskiego 15, 93-590 Lodz, Poland

e-mail: marianwo@mitr.p.lodz.pl

J. Gajda

Department of Biotechnology and Food Science, Institute of General Food Chemistry, Technical University, Stefanowskiego 4/10, 90-924 Lodz, Poland
} 
the dual functions of (i) detoxifying iron, by oxidizing the $\mathrm{Fe}(\mathrm{II})$ ions in solution, and (ii) concentrating iron, by storing the oxidized $\mathrm{Fe}(\mathrm{II})$ ions in its inner protein cavity in the form of a ferrihydrite $\left(\mathrm{Fe}_{2} \mathrm{O}_{3} \cdot n \mathrm{H}_{2} \mathrm{O}\right)$ phosphate mineral core $[1,2]$. It is the only known protein that can bind metal ions in solution and convert them into a solid-phase mineral [3]. The ferritin molecule consists of two main components: the protein shell and a mineral core of hydrated ferric oxide.

Iron-free ferritin molecules (apoferritin) are hollow spheres with an outer diameter of $12 \mathrm{~nm}$, an inner diameter of $8 \mathrm{~nm}$, and a molecular weight of approximately half a million. They are composed of 24 protein subunits. The apoferritin subunit consists of a bundle of four long $\alpha$-helices. The three-dimensional structure of the subunit is well known [4, 5]. Within the subunit, the helices interact to form a hydrophobic core $3.5 \mathrm{~nm}$ long. The central cavity can contain up to $4,500 \mathrm{Fe}(\mathrm{III})$ atoms, which are stored as a ferric oxyhydroxide-phosphate mineral [6-8].

Natural ferritins are composed of various proportions of two subunit types named $\mathrm{H}$ and $\mathrm{L}$ [9-11]. Horse spleen ferritin contains mainly L-chains, and only 10-15\% H-chains [9]. H-chains contain a metal-binding site within the bundle; this site has been associated with the observed ferroxidase activity [4, 12-15]. L-chains appear to confer greater physical stability on assembled ferritin molecules than H-chains, and are superior in ferrihydrite nucleation $[15,16]$.

In the apoferritin, there are two types of channels through which small molecules or ions could gain access to the central cavity of the molecule. These channels are located along the threefold and fourfold axes of symmetry and have very different characters. The six fourfold channels are very hydrophobic, whereas the eight threefold channels are lined with polar groups and are, therefore, hydrophilic. Iron is probably transported through the threefold channels [2, 16-18], whereas the fourfold channel is assumed to transport other small molecules, such as molecular oxygen or reducing agents $[2,16,17]$.

Pores through the apoferritin in the crystalline state are only a few $\AA$ wide. Nevertheless, dynamic structural fluctuations may allow some of the small reductants to enter the protein shell fast enough to interact directly with the core and remove its surface iron [2].

The mobilization of iron from ferritin at appreciable rates requires the use of a suitable reductant to chemically reduce the core. Besides a chemical reducing agent, light or ionizing radiation may be used to trigger the mobilization of iron ions from ferritin. In the present paper, light- and ionizing radiation-induced redox reactions involving horse spleen ferritin are investigated.

\section{Experimental}

\section{Materials}

Horse spleen ferritin and other chemicals were purchased from Sigma-Aldrich.

A stock solution $(0.1 \mathrm{mg} / \mathrm{mL})$ of horse spleen ferritin was prepared in $0.15 \mathrm{M}$ $\mathrm{NaCl}$. The optical absorbance of the stock solution at $280 \mathrm{~nm}$ was 1 . The total 
iron content in ferritin was determined by chemical reduction of the mineral core by $\mathrm{Na}_{2} \mathrm{~S}_{2} \mathrm{O}_{4}$. The concentration of the protein was in the range $0.16-0.53 \mathrm{mg} / \mathrm{mL}$. The optical path of the quartz cell was 0.1 or $0.02 \mathrm{~cm}$. The calculations to determine the total amount of iron per molecule of ferritin were done according to [17].

A stock solution $(12.5 \mathrm{mM})$ of ferrozine-the organic chelator, \{3-(2-pyridyl)5,6-bis(4-phenyl-sulfonic acid)-1,2,4 triazine - was prepared in Millipore deionized water. Saturation with $\mathrm{N}_{2}, \mathrm{~N}_{2} \mathrm{O}$, and $\mathrm{O}_{2}$ was obtained by purging the solutions for $20 \mathrm{~min}$ with high-purity gases immediately prior to illumination or irradiation.

\section{Measurements}

We used a Cary 5E UV-Vis-NIR Varian spectrophotometer to observe the kinetics of chelation of the ferrous ions and all absorption spectra, and a 1-cm quartz cell. The photoreduction of $\mathrm{Fe}$ (III) in the ferritin mineral core was carried out using light pulses generated by an excimer laser COMPex 201 (Lambda Physik). In some experiments, Nd-YAG (NL-100, EKSMA, $355 \mathrm{~nm}$-energy per pulse $30 \mathrm{~mJ}, 532$ $\mathrm{nm}$-energy per pulse $78 \mathrm{~mJ}$, pulse duration $500 \mathrm{ps}$ ) was used as the light source. The $2 \mathrm{~mL}$ of horse spleen ferritin was illuminated by a laser light $(308,355$, or $532 \mathrm{~nm})$ in both the absence and the presence of $1 \mathrm{~mL}$ of ferrozine solution. The steady-state illumination was performed with a 150-W Xe lamp (Bausch and Lomb). The light was filtered through a $10-\mathrm{cm}$ quartz cuvette containing water and an interference filter $(313 \mathrm{~nm})$.

The pulse radiolysis measurements were carried out using a linear electron accelerator ELU-6, which delivered either 4- $\mu$ s pulses (500 Gy) or 1- $\mu$ s pulses (120 Gy).

Kinetic measurements for complexation reactions within milliseconds were performed using the SX 17 MV stopped-flow spectrofluorimeter (Applied Photophysics) with a 1-cm cell. Transient absorption spectra were recorded using a computer-controlled flash photolysis system. The laser used for excitation was a Lambda-Physik COMPex $201 \mathrm{XeCl}$ excimer laser (308 nm, pulse duration about 22 ns, max. energy per pulse $400 \mathrm{~mJ}$ ). The $75-\mathrm{W}$ xenon pulsed lamp (PTI-PowerArclamp housing and lamp power supply LPS220) was the source of the probe flash. The excitation/analysis light geometry was a right-angle. The $200 \mathrm{~mL}$ of sample solution was loaded into the sample reservoir, and as we collected the data, this solution circulated continuously through a $1-\mathrm{cm}$ optical path in the quartz cell. The wavelength of the probe light flash was varied using an Acton Research monochromator SpectraPro-275. The analyzing light was monitored by a Hamamatsu R3896 photomultiplier, and its output was recorded by a Tektronix 680C oscilloscope. The energy of the laser light beam was attenuated by glass plates or was increased by a cylinder quartz lens. The energy of the laser beam at the sample cell position was measured with a Coherent (FieldMaster-LM-P10i) energy meter. Furthermore, the lasers and the linear electron accelerator were used with a repetition ratio of $1 \mathrm{~Hz}$. 


\section{Results and discussion}

Many reducing agents and chelators can be used to trigger iron release, as presented in several studies $[15,17,18]$. In the present study, light or ionizing radiation and ferrozine were chosen as the reducing agent and the chelator, respectively. The ferrous ion, $\mathrm{Fe}(\mathrm{II})$, becomes highly absorbing to visible light when it forms a complex with the organic chelator, ferrozine. This very stable complex, $\mathrm{Fe}$ (ferrozine $)_{3}^{4-}$, is dark purple and can be spectrophotometrically detected at the wavelength of $562 \mathrm{~nm}$, even at a very low concentration, due to the high extinction coefficient of $27,900 \mathrm{dm}^{3} \mathrm{~mol}^{-1}$ [17].

In photochemical studies, we illuminated the sample of ferritin $(0.1 \mathrm{mg} / \mathrm{mL})$ with laser light, wavelength $308 \mathrm{~nm}$, in anaerobic conditions. We illuminated the cells filled with $2 \mathrm{~mL}$ of the ferritin solution using different numbers of laser pulses. We then transferred the cells into the spectrophotometer chamber and, after $3 \mathrm{~min}, 1 \mathrm{~mL}$ of ferrozine solution was added. The recorded absorption spectrum was, in each case, typical for Fe(II)-ferrozine complex (Fig. 1). To study the kinetics of the complexation reaction, we recorded the build up of absorbance of $\mathrm{Fe}(\mathrm{II})$-ferrozine complex at $562 \mathrm{~nm}$. One of the representative kinetic traces obtained in the photochemical experiment is shown as curve 1 in Fig. 1. It is pertinent to note that the ferrous ions formation was not detected after the addition of ferrozine into the sample of ferritin without illumination.

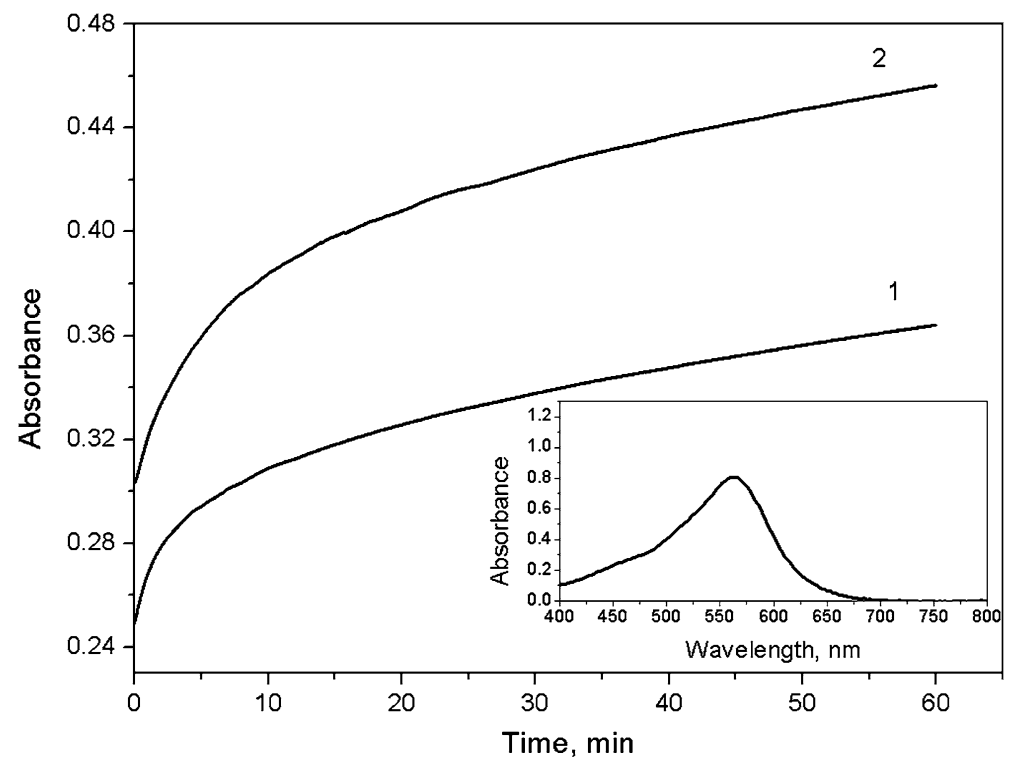

Fig. 1 The kinetics of $\mathrm{Fe}(\mathrm{II})$ release from ferritin $(0.09 \mathrm{mg} / \mathrm{mL})$ following: (1) photoreduction and (2) radiolysis (10 pulses, pulse duration $4 \mu \mathrm{s}$, dose 500 Gy per pulse), monitored by the complexation of $\mathrm{Fe}(\mathrm{II})$ with ferrozine (11.4 mM). Insert: the absorption spectrum of Fe(II)-ferrozine complex obtained by the chemical reduction of $0.53 \mathrm{mg} / \mathrm{mL}$ ferritin by $\mathrm{Na}_{2} \mathrm{~S}_{2} \mathrm{O}_{4}$ in the presence of ferrozine $(8.3 \mathrm{mM})$. Optical path, $0.02 \mathrm{~cm}$ 
The mineral core photoreduction process was monitored by the kinetics of $\mathrm{Fe}$ (II) release from ferritin using a spectrophotometer. Samples of ferritin $(2 \mathrm{~mL}$ of $0.1 \mathrm{mg} / \mathrm{mL}$ solution) were illuminated with different numbers of pulses $(1,5,10,20$, and 30). Three minutes after mineral core photoreduction, the chelator agent ferrozine ( $1 \mathrm{~mL}$ of $12.5 \mathrm{mM}$ solution) was added to each sample, and then immediately afterwards, the kinetics of the complexation process was followed. In this series of experiments, we used laser pulses of energy $70 \mathrm{~mJ} / \mathrm{cm}^{2}$, which were sufficient to observe the photoreduction process. The amount of photoreduced $\mathrm{Fe}$ (II) increased with the number of pulses up to 20, as shown in Fig. 2. Beyond the 20 pulses used for illumination, we did not observe any further increase in absorption after the chelating agent was added ( 3 min after photoillumination). Within the experimental error, the kinetics of the complexation process are the same, despite the different initial concentrations of Fe(II)-ferrozine complex: 5.30, 6.52, 7.81, 8.88 , or $8.96 \mu \mathrm{M}$. Furthermore, under our experimental conditions, the kinetic pattern does not depend upon the presence of the oxygen. In further experiments, we used five pulses of laser light to photoreduce the mineral core, as we noted that this number of pulses generated a sufficient amount of Fe(II)-ferrozine complex for absorbance studies.

Moreover, we investigated whether the time elapsed after illumination can influence the chelating process. Many samples were photoilluminated ( 5 pulses of energy, $70 \mathrm{~mJ} / \mathrm{cm}^{2}$ each) and the chelator-ferrozine-was added to each sample after $1,2,4,6,9,12$, or $15 \mathrm{~min}$. Then, we followed the complexation process for the above mentioned times after illumination under the same conditions. In each case, we recorded the kinetic curve in the time window of 15 min (Fig. 3). We observed

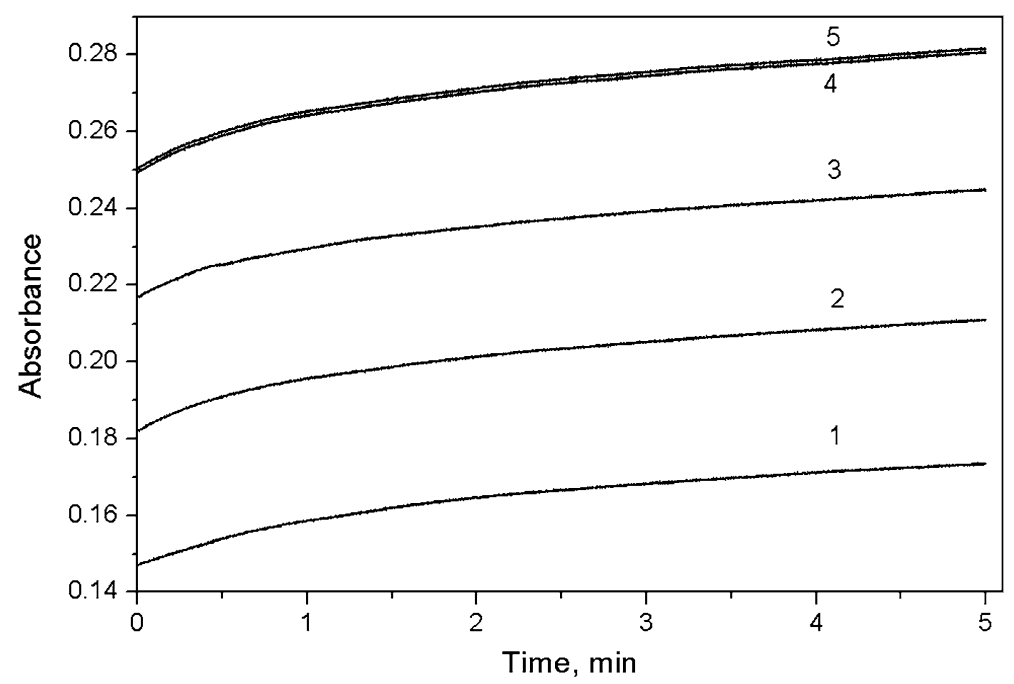

Fig. 2 The kinetics of the complexation process of iron ions released from ferritin $(0.067 \mathrm{mg} / \mathrm{mL})$ by ferrozine (4.2 $\mathrm{mM}$ ) recorded after irradiation consisting of: (1) one pulse, (2) 5 pulses, (3) 10 pulses, (4) 20 pulses, (5) 30 pulses. The complexation agent was added 3 min after illumination, and at that moment, we started recording the kinetics (time $=0$ ) 


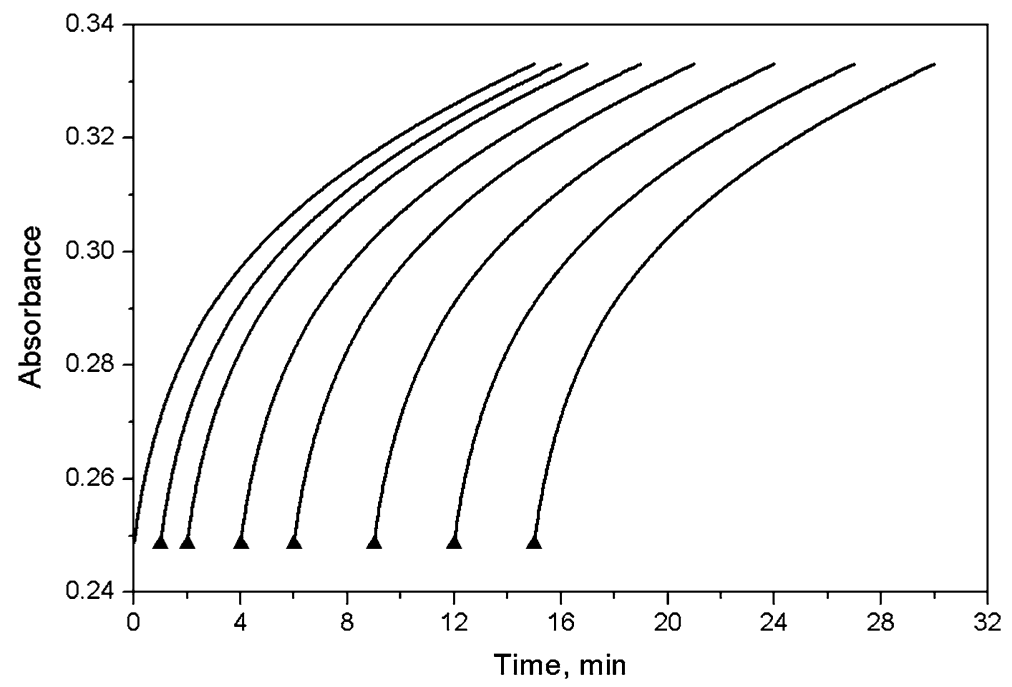

Fig. 3 The kinetics of ferrous ions release from ferritin $(0.087 \mathrm{mg} / \mathrm{mL})$ following photoirradiation $(10$ pulses, $70 \mathrm{~mJ} / \mathrm{cm}^{2}$ ) monitored by the complexation of $\mathrm{Fe}(\mathrm{II})$ with ferrozine $(16.3 \mathrm{mM})$. The points (filled triangles) represent the initial absorbance of $\mathrm{Fe}(\mathrm{II})$-ferrozine complex at various lengths of time elapsed after photoirradiation. In each case, $2 \mathrm{~mL}$ of ferritin $(0.1 \mathrm{mg} / \mathrm{mL})$ was photoirradiated and $0.3 \mathrm{~mL}$ of the chelator (ferrozine, $125 \mathrm{mM}$ ) was added after the time shown in the plot

that the initial absorbance in each experiment was exactly the same; moreover, the kinetic patterns were the same. This means that the time elapsed after illumination does not influence the chelating process and that reduced ferritin without chelator is the Fe(II)-storage molecule in a long time scale. Figures 1, 2, and 3 show that the initial absorbance of $\mathrm{Fe}(\mathrm{II})$-ferrozine complex is formed extremely quickly (time scale on the order of a few seconds). This can be explained if we assume that the fraction of $\mathrm{Fe}(\mathrm{II})$ is easily accessible to the chelator. Although the core contains most of the $\mathrm{Fe}(\mathrm{II})$, some specific iron also resides in the channels, and probably at the surface of the ferritin protein accessible to chelators and reductants. It seems that part of the $\mathrm{Fe}$ (II) is located in the entrance to the channels and at the surface of the protein. We postulate that this fraction is easily complexed. Several events may be responsible for the slow complexation, namely, nonclassical diffusion of $\mathrm{Fe}$ (II) through the channels, trapping of Fe(II) inside the protein shell, and retardation of the complexation involved by the heterogeneity of the system. We believe that the diffusion of $\mathrm{Fe}(\mathrm{II})$ from the protein interior onto the surface is responsible for the kinetics pattern of the Fe(II)-ferrozine complex build-up. In order to confirm this hypothesis we studied the influence of the concentration of ferrozine on the kinetics of $\mathrm{Fe}$ (II) release from ferritin. As presented in Fig. 4, the kinetics depend upon the chelator concentration at the beginning of the process and only slightly depends upon it after $14 \mathrm{~min}$. We may explain this if we assume that there is a distribution of specific sites in which $\mathrm{Fe}$ (II) is trapped. While there are sites where $\mathrm{Fe}$ (II) is more easily accessible for the complexation agent, there are others where $\mathrm{Fe}$ (II) is more strongly captured. It seems reasonable to conclude that, at a given concentration of 


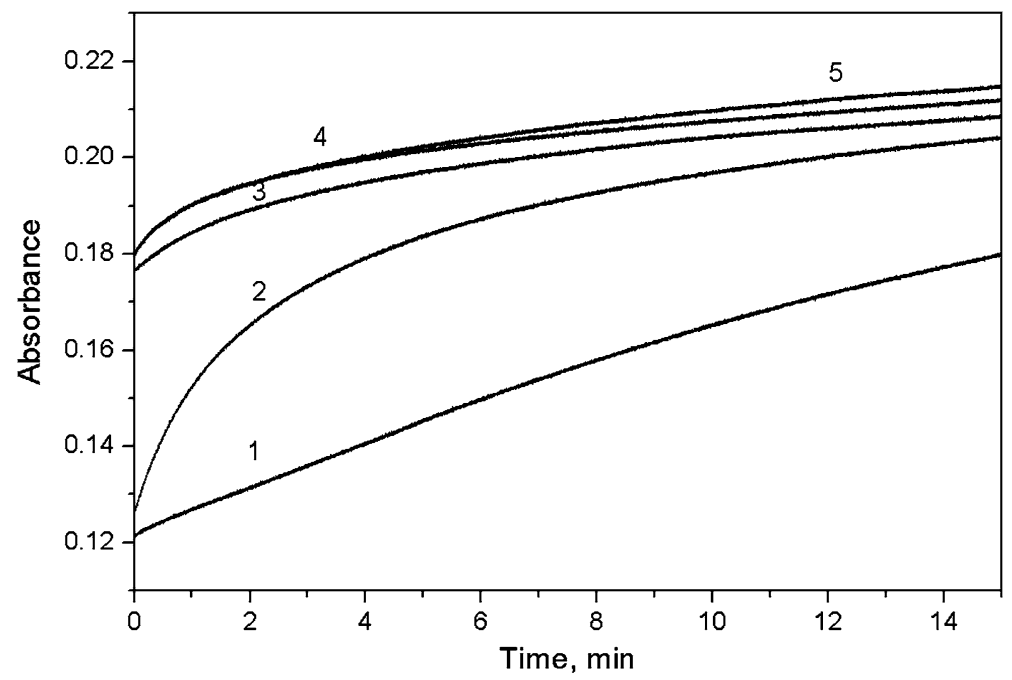

Fig. 4 The plot of the absorbance of $\mathrm{Fe}$ (ferrozine) ${ }_{3}^{4-}$ complex, obtained from the amount of $\mathrm{Fe}$ (II) released from ferritin $(0.067 \mathrm{mg} / \mathrm{mL})$ following photoreduction versus time at various chelator concentrations: (1) $0.8 \mathrm{mM}$; (2) $1.6 \mathrm{mM}$; (3) $2.5 \mathrm{mM}$; (4) $3.3 \mathrm{mM}$; (5) $4.2 \mathrm{mM}$

the complexation agent, a small fraction of $\mathrm{Fe}(\mathrm{II})$ can survive on the surface for quite a long time; in other words, the energy of the protein-Fe(II) interaction changes over time, therefore, the energy of the trap varies as well. We postulate that the observed higher rate of complexation at a higher concentration of ferrozine is a result of the competition between the reorganization of the $\mathrm{Fe}$ (II) binding trap on the protein surface (surface sites) and an increase of the frequency of the surface encounter by ferrozine. In the long time scale, we observe a similar degree of complexation at different ferrozine concentrations. In our opinion, this is determined by the slow diffusion of $\mathrm{Fe}$ (II) from the iron core into the surface or bulk solution. We believe that, just after photoreduction, a certain equilibrium exists between the $\mathrm{Fe}$ (II) concentration inside and outside of the protein shell. The equilibrium is disturbed by the presence of the chelator, ferrozine. Hence, the kinetics of $\mathrm{Fe}$ (II) release from ferritin is limited by the redistribution of Fe(II) within channels and among surface sites. A chelator helps Fe(II) to exit the molecule. Small Fe(II) chelators which mobilize Fe(II) from ferritin over a period of hours or days may also enter the molecule and leave bearing iron as the Fe(II)-chelate complex. Penetration of the ferritin protein coat by small reductants and chelators has been a controversial subject [19]. We suppose, however, that ferrozine is probably too large to fit the threefold channels, but influences the removal of $\mathrm{Fe}(\mathrm{II})$ by an efficient chelation process on both the surface and outside the protein shell.

It is possible that the detailed mechanism of complexation can be modified by the transfer of protons [20]. Watt et al. [20] proposed that the reduction of $\mathrm{Fe}(\mathrm{III})$ in horse spleen ferritin is accompanied by an uptake of two protons per electron from the surrounding medium. In the present work, we were not able to study the proton transfer. We will, however, study this at different $\mathrm{pH}$ levels in the future. 
In our view, in the mechanism of formation of $\mathrm{Fe}(\mathrm{II})$-ferrozine complex, the process of reaching the surface of the protein by $\mathrm{Fe}(\mathrm{II})$ is crucial. Figure 1 illustrates that, in two independent experiments in which we reduced Fe(III) by two different methods (photochemical vs. radiolytical), the kinetic patterns are very similar. It is obvious that the reduction reaction itself is not important for the kinetics. In this case, the kinetics are determined by the release of Fe(II) from the interior of the protein. In the photochemical and radiolytical studies, we dealt with a low percentage of $\mathrm{Fe}$ (II) reduction. In our experiments, the iron load of ferritin is 1,730 $\mathrm{Fe}$ (III) per ferritin molecule (see the Experimental section). Figure 2 shows that the maximum concentration of photoreleased Fe(II) from ferritin $(0.067 \mathrm{mg} / \mathrm{mL})$ is about $1.08 \mu \mathrm{M}$, corresponding to $5.9 \%$ of the total iron. Thus, $100 \mathrm{Fe}(\mathrm{II})$ ions can be photoreleased per ferritin molecule.

The previous [21] and present studies indicate that photoreduction can be a useful way of removing Fe(II) from ferritin. To further understand some the mechanisms of the photoreduction of Fe(III), we conducted several flash photolysis experiments with different intensities of laser light. Illumination of the ferritin solution using both low- and high-intensity UV light leads to the bleaching of the absorbance of ferritin. Photoreduction induces the release of a $\mathrm{Fe}$ (II) from ferritin only in the presence of a $\mathrm{Fe}(\mathrm{II})$ chelator: ferrozine or phenanthroline. Laser photolysis with low-intensity pulses (below $70 \mathrm{~mJ} / \mathrm{cm}^{2}$ for $308 \mathrm{~nm}$ ) showed that the photoreduction of $\mathrm{Fe}(\mathrm{III})$ in the mineral core occurs (the spectrum below $350 \mathrm{~nm}$-open circlesFig. 5) without formation of transient species absorbing light above $350 \mathrm{~nm}$ on the microsecond time scale (Fig. 5). Illumination of the ferritin solution with several laser pulses leads to a permanent bleaching of its absorbance. The change in

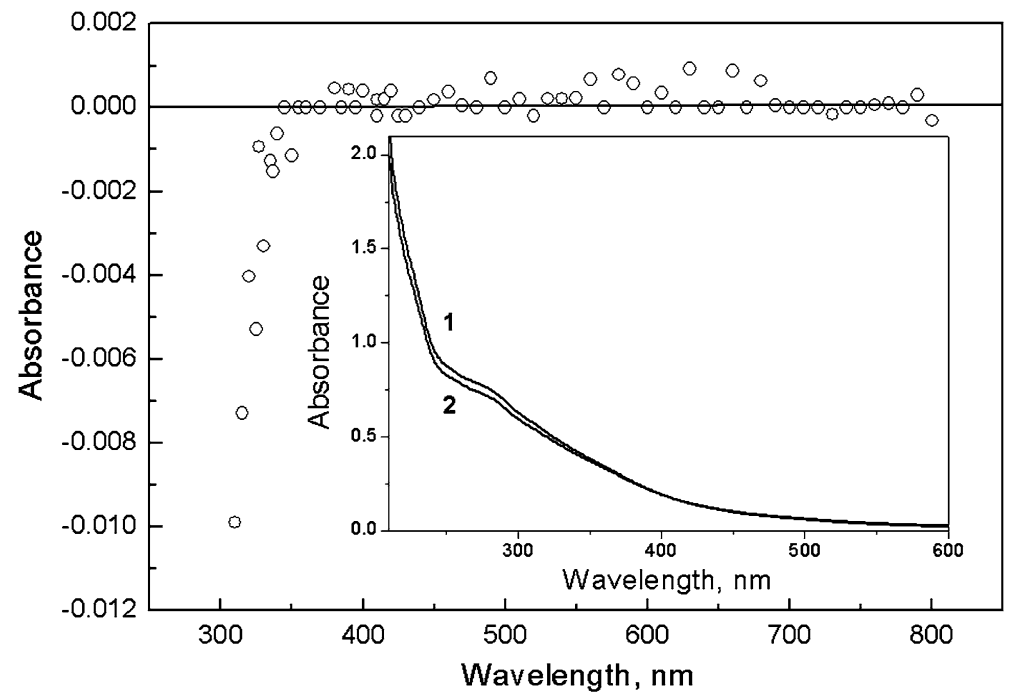

Fig. 5 The absorption spectrum recorded $35 \mu$ s upon the laser pulse irradiation (25 ns pulse duration, energy $70 \mathrm{~mJ} / \mathrm{cm}^{2}$ ) of the $\mathrm{N}_{2}$ saturated solution containing ferritin $(0.1 \mathrm{mg} / \mathrm{mL})$. Insert: (1) absorption spectrum of ferritin $(0.0076 \mathrm{mg} / \mathrm{mL})$ before and (2) after laser pulse illumination (50 pulses of $308 \mathrm{~nm}, 50$ $\mathrm{mJ}$ per pulse) 
absorbance of ferritin solution is shown in the insert of Fig. 5. When ferritin is exposed to low-intensity light from an Xe lamp $\left(\sim 10^{14}\right.$ photon/s, interference filter $313 \mathrm{~nm}$ ), photoreduction of its endogenous iron takes place. Low laser light intensity illumination (about $50 \mathrm{~mJ} / \mathrm{cm}^{2}$ ) also leads to $\mathrm{Fe}(\mathrm{II})$ release. Laulhère et al. [21] reported that the mineral core is the target for the light (when ferritin is illuminated); our findings agree with these studies at low light intensities. It is well known that certain $\mathrm{Fe}$ (III) complexes undergo photoreduction during daylight illumination, which results in the production of $\mathrm{Fe}(\mathrm{II})$ and the associated free-radical species [22, 23]. Additional proof that the iron core is the main site of the photoreduction was obtain by $\mathrm{Nd}-\mathrm{YAG}$ laser-pulse excitation at $532 \mathrm{~nm}$. Upon illumination of the ferritin solution at $532 \mathrm{~nm}$, the light is only absorbed by mineral core, and not by protein, but we were still able to observe the Fe(II) release. This means that the protein shell does not participate efficiently in the photoreduction of ferritin. By the illumination of ferritin solution with low-intensity light, the electron loss center becomes localized exclusively at the mineral core.

When the laser light intensity reached the value of about $400 \mathrm{~mJ} / \mathrm{cm}^{2}$, we observed the formation of short-lived species with a spectral maximum at $720 \mathrm{~nm}$, which is characteristic of a hydrated electron [24]. Figure 6 shows the absorption spectrum recorded $195 \mathrm{~ns}$ after the laser pulse irradiation ( $25 \mathrm{~ns}$ pulse duration, 420 $\mathrm{mJ} / \mathrm{cm}^{2}$ energy) of the $\mathrm{N}_{2}$-saturated solution containing only ferritin $(0.1 \mathrm{mg} / \mathrm{mL})$. The decay of the solvated electron absorbance with the rate constant $k=9.5 \times 10^{6}$ $s^{-1}$ is illustrated in the insert of Fig. 6. To verify that our transient absorption was, indeed, due to a hydrated electron, we performed an additional experiment in the

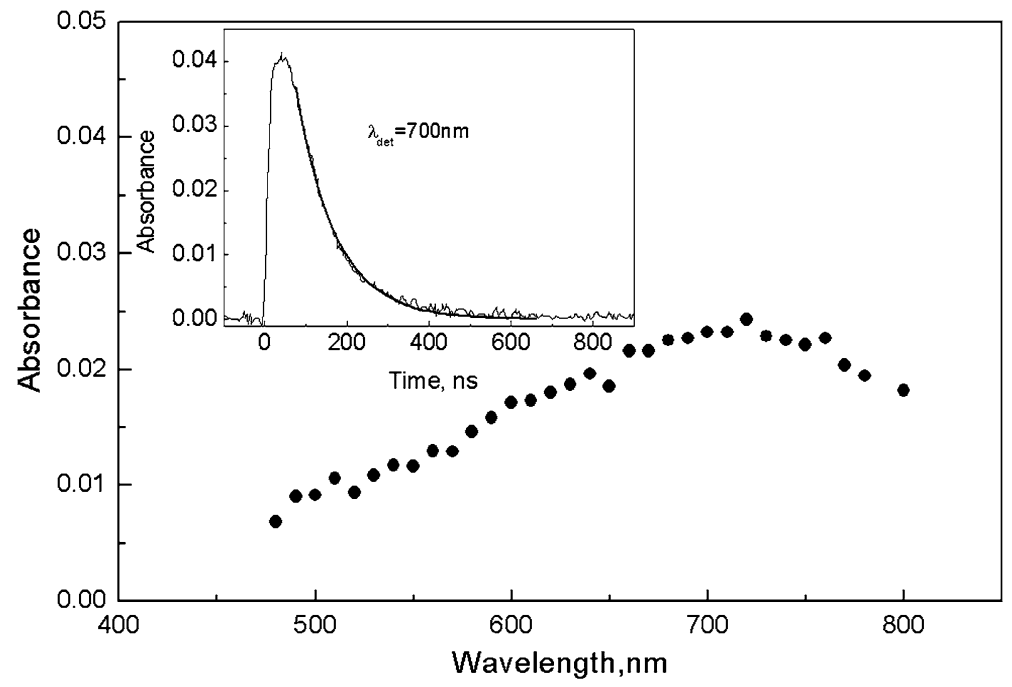

Fig. 6 The absorption spectrum recorded $120 \mathrm{~ns}$ upon the laser pulse irradiation (25 ns pulse duration, $420 \mathrm{~mJ} / \mathrm{cm}^{2}$ energy) of the $\mathrm{N}_{2}$-saturated solution containing ferritin $(0.1 \mathrm{mg} / \mathrm{mL})$. Insert: the decay of the absorbance of the solvated electron produced by pulse irradiation $\left(308 \mathrm{~nm}, 420 \mathrm{~mJ} / \mathrm{cm}^{2}\right)$ of the $\mathrm{N}_{2}$-saturated solution of ferritin $(0.1 \mathrm{mg} / \mathrm{mL})$ 
presence of an electron scavenger $-\mathrm{N}_{2} \mathrm{O}$. We found that $\mathrm{N}_{2} \mathrm{O}$-saturated ferritin solution exposed to high-intensity light does not produce a hydrated electron, because of the scavenging of the hydrated electron (produced by photoionization of the protein shell or the mineral core) by $\mathrm{N}_{2} \mathrm{O}$. This experiment confirms that the spectrum shown in Fig. 6 is, indeed, due to the hydrated electron. In the photochemical studies using highly intense laser pulses $\left(420 \mathrm{~mJ} / \mathrm{cm}^{2}\right)$, we observed the formation of $\mathrm{e}_{\mathrm{aq}}^{-}$, but our results do not indicate whether the electron is localized inside the ferritin or is solvated in the bulk water. From flash photolysis studies, we can prove that $\mathrm{e}_{\mathrm{aq}}^{-}$is involved in the reduction process. To investigate the importance of the protein shell in the photoionization of ferritin, we performed flash photolysis of apoferritin solution. We established that the photoexcitation of apoferritin with high light intensities $\left(400 \mathrm{~mJ} / \mathrm{cm}^{2}\right)$ leads to hydrated electron formation. The yield of the $\mathrm{e}_{\mathrm{aq}}^{-}$in this case is much lower than that obtained during the laser flash photolysis of ferritin. This observation provides evidence that the protein shell participates in $\mathrm{e}_{\mathrm{aq}}^{-}$generation. The lower yield of photoionization of apoferritin with respect to ferritin clearly shows that the mineral core is also involved in $\mathrm{e}_{\mathrm{aq}}^{-}$formation.

$\mathrm{Fe}$ (III) within ferritin can be reduced by a solvated electron (which was confirmed in the preliminary pulse radiolysis experiment). Other possibilities include direct photoreduction of the mineral core, as shown by Laulhère et al. [21, $25,26]$ or photoinduced electron transfer from the triplet state of photoexcited tryptophan to the core. The present results do not allow us to determine the detailed mechanism of photoreduction.

The photochemical reduction of Fe(III) inside the ferritin consists of several processes depending on the light intensity. Ferritin exposed to low-intensity light undergoes direct photoreduction in the mineral core. There are two possibilities in the photoreduction of $\mathrm{Fe}$ (III) in the illumination of ferritin with high light intensity (above $400 \mathrm{~mJ} / \mathrm{cm}^{2}$ ). The first results in the generation of a hydrated electron which triggers iron release from ferritin. The mineral core as well as the protein shell participate directly in the photoreduction of Fe(III). This is a minor pathway for the $\mathrm{Fe}$ (II) formation process. On the other hand, the second possibility is a major pathway, and is simply the photoreduction of the mineral core.

In radiolytic studies, we found that solvated $\mathrm{e}_{\mathrm{aq}}^{-}$and the superoxide anion radical generated by electron beam irradiation can release iron from ferritin (see Fig. 7). As shown in Fig. 7, $\mathrm{O}_{2}^{--}$is more efficient in inducing the release of iron from the ferritin than $\mathrm{e}_{\mathrm{aq}}^{-}$. In electron pulse radiolysis of dilute aqueous solution of ferritin, the energy is almost exclusively absorbed by water molecules. The deposition of energy results in the production of the reactive species, namely, the hydrated electron, the hydroxyl radical, and the hydrogen atom. These radicals may be transformed into single reducing or oxidizing radicals, via the use of suitable scavengers. In the present study of the release of Fe(II) from ferritin, we have chosen t-butanol as the scavenger of ${ }^{\circ} \mathrm{OH}$ radicals, which are converted into unreactive hydroxyalkyl radical ${ }^{\circ} \mathrm{CH}_{2}\left(\mathrm{CH}_{3}\right)_{2} \mathrm{COH}$. The hydrated electron is a powerful reductant. A feature of the $\mathrm{e}_{\mathrm{aq}}^{-}$is that it may react by tunneling over long distances. The electron can also react in its presolvated ("dry") state. Due to the strong optical absorption in the visible range of the spectrum, we were able to study reduction reactions with ferritin 


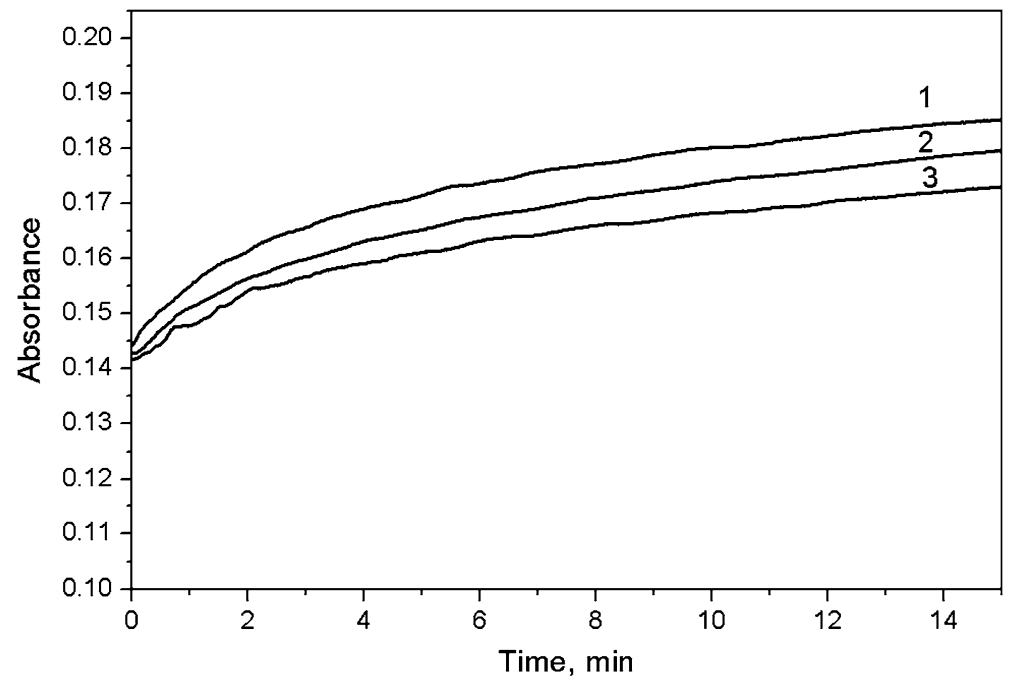

Fig. 7 The kinetics of ferrous ions release from ferritin $(0.067 \mathrm{mg} / \mathrm{mL})$ following radiolysis monitored by the complexation of $\mathrm{Fe}(\mathrm{II})$ with ferrozine $(4.2 \mathrm{mM})$. (1) Oxygen-saturated solution, (2) aerated solution, (3) nitrogen-saturated solution. In each case, $2 \mathrm{~mL}$ of ferritin $(1 \mathrm{mg} / \mathrm{mL})$ was irradiated with 10 pulses of a $1-\mu$ s electron beam (dose 125 Gy per pulse) and $1 \mathrm{~mL}$ of the ferrozine $(12.5 \mathrm{mM})$ was added 3 min after radiolysis

using pulse radiolysis combined with kinetic spectrometry. The hydrated electron is effective in reducing many $\mathrm{Fe}$ (III) complexes, including aquo-metal ion (rate constant $6 \times 10^{10} \mathrm{dm}^{3} \mathrm{~mol}^{-1} \mathrm{~s}^{-1}$ [24]). In our pulse radiolysis studies, we have found that ferritin is not very reactive towards $\mathrm{e}_{\mathrm{aq}}^{-}$. The importance of $\mathrm{O}_{2}^{\bullet-}$ as an effective reducing agent for iron releasing from ferritin is well established [27]. Previous work [28] has shown that $\mathrm{O}_{2}^{\bullet-}$ generated from ${ }^{137} \mathrm{Cs}$ gamma radiation resulted in efficient iron release from ferritin. Our findings are consistent with this study.

In contradiction to Reif et al. [28], we found that ferrozine added to the ferritin solution immediately after a short burst of $\mathrm{O}_{2}^{\bullet-}$ generated by pulse radiolysis did yield detectable amounts of $\mathrm{Fe}(\mathrm{II})-$ ferrozine complex. Our results suggest that the presence of the chelator at the time of reduction is not necessary to generate $\mathrm{Fe}$ (II) detectable with ferrozine. The rate of $\mathrm{e}_{\mathrm{aq}}^{-}$scavenging by ferritin does not depend strongly on ferritin concentration (see Fig. 8) because of the electrostatic repulsion between the charge of solvated electron and the high negative charge on the protein surface. This observation brings up the question of the mechanism of electron transfer from the water phase into the ferritin interior. It is possible that the electron produced by the ionizing radiation penetrates into/on the ferritin either as a dry electron or in the tunneling process.

The most important observation in our work is that Fe(II) can be trapped within ferritin for a significant period of time-at least several hours. Therefore, all reduction processes of the $\mathrm{Fe}(\mathrm{III})$ within the ferritin interior can occur without a chelator. It is important to note that we conducted our radiolytical studies under 


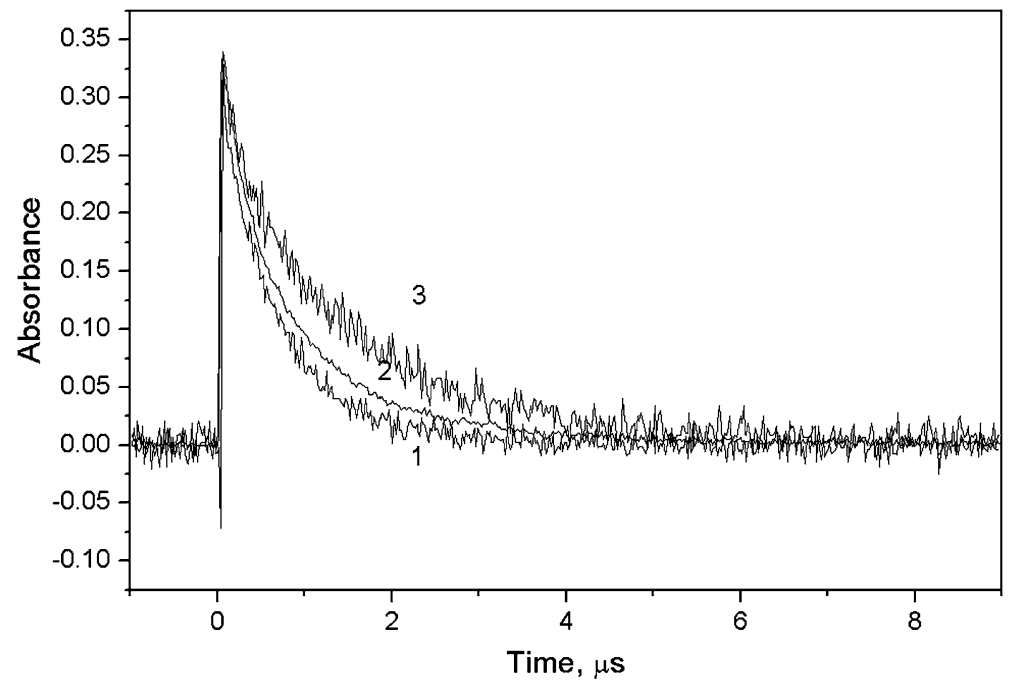

Fig. 8 Decay traces of the transients formed in $\mathrm{N}_{2}$-saturated aqueous solutions of ferritin (1) $2 \mathrm{mg} / \mathrm{mL}$, (2) $0.1 \mathrm{mg} / \mathrm{mL}$, and (3) in neat water upon the pulse radiolysis. All kinetic patterns were recorded at 700 $\mathrm{nm}$ in the presence of $0.1 \mathrm{M} \mathrm{t}$-butanol (pulse duration $17 \mathrm{~ns}$, dose 60 Gy per pulse)

conditions which eliminated the oxidative damage of ferritin by the presence of tertbutanol (an ${ }^{\bullet} \mathrm{OH}$ scavenger) in $\mathrm{N}_{2}$-saturated solution. The irradiation of the ferritin solution in the absence of t-butanol promoted the damage of the protein. Although this process is important from the biological point of view (as pointed out by Reif et al. [28] - ferritin may serve as a pathological source of iron upon exposure to ionizing radiation), we were unable to study it due to the strong absorbance of the decomposition products of ferritin. The reactions which take place during the radiolysis of ferritin are accompanied by damage of the protein shell by ${ }^{\circ} \mathrm{OH}$ radicals. This damage is prevented by the presence of the ${ }^{\bullet} \mathrm{OH}$ radical scavengers, e.g., t-butanol. We have shown that subsequent removal of the $\mathrm{Fe}$ (II) by redox reaction depends upon the chelating agent-ferrozine or phenanthroline. Most of our experiments were conducted with ferrozine due to the high extinction coefficient of $\mathrm{Fe}(\mathrm{II})-$ ferrozine complex. We found that the complexation process occurs quite rapidly. The complexation of $\mathrm{Fe}(\mathrm{II})(19.6 \mu \mathrm{M})$ with ferrozine $(4.17,6.25,8.33,12.5$ $\mathrm{mM}$ ) was studied at $298 \mathrm{~K}$ using sequential mixing stopped-flow techniques. The rate of the reaction increased linearly with ferrozine concentration, giving the value $2.65 \times 10^{4} \mathrm{dm}^{3} \mathrm{~mol}^{-1} \mathrm{~s}^{-1}$ for the rate constant of the complexation process (Fig. 9). This complexation rate constant (the value for the pseudo-first-order constant equals $111 \mathrm{~s}^{-1}$ for a ferrozine concentration of $4.15 \mathrm{mM}$ ) is evidently higher with respect to the analogous process observed in the photochemical reduction as studied by the laser flash photolysis technique. In this experiment, we pulsed the sample containing both ferritin $(0.067 \mathrm{mg} / \mathrm{mL})$ and a chelator, ferrozine (4.2 mM). In the longer time scale, we observed a buildup of the Fe(II)-ferrozine complex absorption band. The kinetics of complexation of the photoreleased Fe(II) 


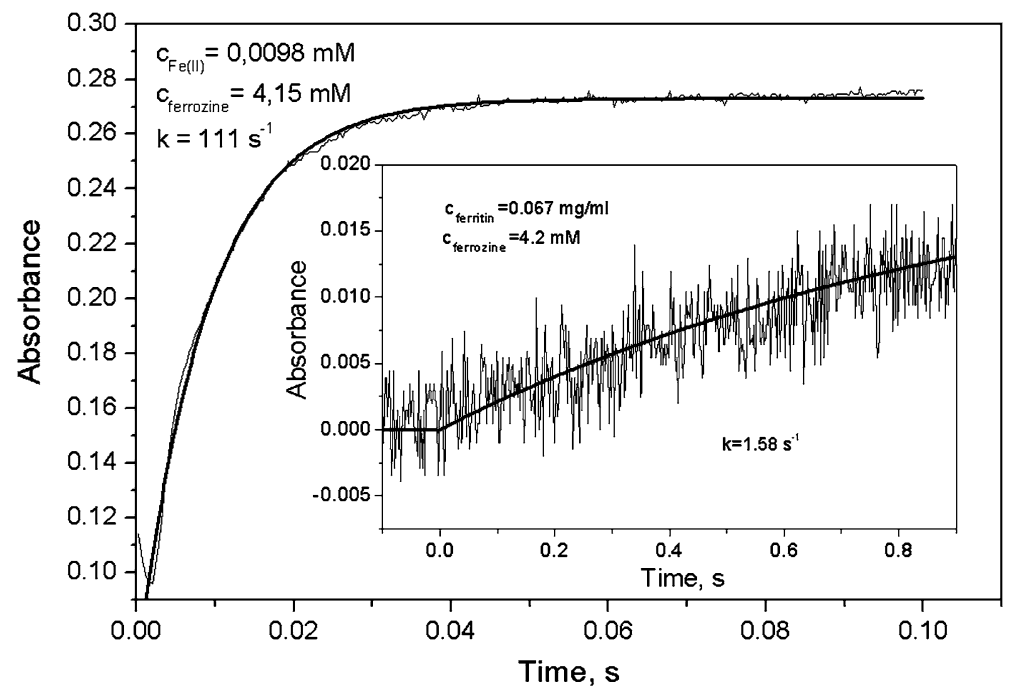

Fig. 9 The stopped-flow measurement of the kinetics of the process of Fe(II) $(9.8 \mu \mathrm{M})$ complexation by ferrozine $(4.17 \mathrm{mM})$. Insert: transient absorption recorded at $562 \mathrm{~nm}$ following pulse laser irradiation $\left(308 \mathrm{~nm}, 70 \mathrm{~mJ} / \mathrm{cm}^{2}\right)$ of the solution containing ferritin $(0.067 \mathrm{mg} / \mathrm{mL})$ and ferrozine $(4.2 \mathrm{mM})$

by ferrozine, observed in the flash photolysis experiment, is shown in the insert of Fig. 9. The pseudo-first-order rate constant calculated from the kinetic curve is $k=1.58 \mathrm{~s}^{-1}$.

A similar process in pulse radiolysis studies cannot be observed because of the fast, efficient scavenging of $\mathrm{e}_{\mathrm{aq}}^{-}$by a chelating agent, ferrozine. Our results also suggest that redox agents (methyl viologen or diquat cation radical) can induce iron mobilization without entering into the ferritin interior. Watt et al. [29] presented a similar conclusion. The lack of direct interaction of the redox reagent with the mineral core means that the electron can be transferred by a channel or by a protein shell. It is difficult to prove experimentally that the electron is transferred via a channel, although such a transfer is quite possible. In the case of $\mathrm{O}_{2}^{\bullet-}$ and $\mathrm{e}_{\mathrm{aq}}^{-}$, both reductants are small enough to enter channels and react with $\mathrm{Fe}(\mathrm{III})$ in the ferritin interior. Our pulse radiolytic studies demonstrate definitively that an electron can be trapped by the protein shell and, subsequently, scavenged by the mineral core. Thus, the long-distance electron transfer can occur directly through a ferritin protein shell which is $20-25-\AA$ thick. In addition to reduction mediated by channel- or corebound $\mathrm{Fe}(\mathrm{II})$, it is possible that long-distance electron transfer occurs by electron tunneling through the ferritin protein shell, as was suggested by Watt et al. [29]. It is evident from our pulse radiolysis studies that there is a transient product of the reaction between radiolytically generated electron and ferritin. To gain a proper understanding of the mechanism of $\mathrm{Fe}$ (II) release from ferritin, this product needs to be recognized and characterized. We are currently conducting a pulse radiolysis study using apoferritin to elucidate the role of the protein shell in the early redox events involved in iron reduction and mobilization. 


\section{Conclusions}

In summary, we conclude that the reduction and mobilization of iron from ferritin mineral core consists of several reactions: (1) reduction by light or ionizing radiation without using any additional chemical reductants; (2) Fe(II) trapping in the ferritin interior for a long period, on the order of at least several hours; (3) restricted diffusion of $\mathrm{Fe}(\mathrm{II})$ via threefold channels; (4) complexation of $\mathrm{Fe}$ (II) by ferrozine or phenanthroline. In our radiolytic studies, electron transfer from the external reductant or reductants through the protein shell into the mineral core occurs. It appears that solvated electron can reduce Fe(III) which is trapped in the ferritin interior both by the diffusion or tunneling through the ferritin channels and by the intermediate stage, i.e., the reduction of the protein and subsequent redox process leading to the generation of $\mathrm{Fe}(\mathrm{II})$. Our present study is devoted to the elucidation of the way in which electrons are delivered to the Fe(III) core. In photochemical experiments, in contrast to pulse radiolysis studies, the mineral core is directly the site of redox reactions. It has been previously determined [30] that, in the absence of chelators, the reduced core of ferritin is stable to iron loss. Our results confirm this observation.

Acknowledgments This work was supported by the Polish Committee for Scientific Research (in part, KBN Project 3 T 09A 03317 and COST Action CM0603; DPN/N4/COST/2009). We thank the Foundation for Polish Science for the financial support (Project FASTKIN 19/1 and SUBIN 14/2000). We also thank Professor Lidia Gębicka for the help with the stopped-flow kinetic measurements.

Open Access This article is distributed under the terms of the Creative Commons Attribution Noncommercial License which permits any noncommercial use, distribution, and reproduction in any medium, provided the original author(s) and source are credited.

\section{References}

1. G.S. Waldo, E.C. Theil, in Comprehensive Supramolecular Chemistry, Bioinorganic Systems, ed. by K.S. Süslick (Pergamon Press, Oxford, 1996), pp. 65-89

2. P.M. Harrison, P. Arosio, The ferritins: molecular properties, iron storage function and cellular regulation. Biochim. Biophys. Acta 1275, 161-203 (1996)

3. A.S. Pereira, W. Small, C. Krebs, P. Tavares, D.E. Edmondson, E.C. Theil, B.H. Huynh, Direct spectroscopic and kinetic evidence for the involvement of a peroxodiferric intermediate during the ferroxidase reaction in fast ferritin mineralization. Biochemistry 37, 9871-9876 (1998)

4. D.M. Lawson, P.J. Artymiuk, S.J. Yewdall, J.M.A. Smith, J.C. Livingstone, A. Treffry, A. Luzzago, S. Levi, P. Arosio, G. Cesareni, C.D. Thomas, W.V. Shaw, P.M. Harrison, Solving the structure of human $\mathrm{H}$ ferritin by genetically engineering intermolecular crystal contacts. Nature 349, 541-544 (1991)

5. N.D. Chasteen, P.M. Harrison, Mineralization in ferritin: an efficient means of iron storage. J. Struct. Biol. 126, 182-194 (1999)

6. P.M. Harrison, S.C. Andrews, P.J. Artymiuk, G.C. Ford, J.R. Guest, J. Hirzmann, D.M. Lawson, J.C. Livingstone, J.M.A. Smith, A. Treffry, S.J. Yewdall, Probing structure-function relations in ferritin and bacterioferritin. Adv. Inorg. Chem. 36, 449-486 (1991)

7. P.D. Hempstead, A.J. Hudston, P.J. Artymiuk, S.C. Andrews, M.J. Banfield, J.R. Guest, P.M. Harrison, Direct observation of the iron binding sites in a ferritin. FEBS Lett. 350, 258-262 (1994)

8. S. Mann, J.V. Bannister, R.J.P. Williams, Structure and composition of ferritin cores isolated from human spleen, limpet (Patella vulgata) hemolymph and bacterial (Pseudomonas aeruginosa) cells. J. Mol. Biol. 188, 225-232 (1986) 
9. P. Arosio, T.G. Adelman, J.W. Drysdale, On ferritin heterogeneity. Further evidence for heteropolymers. J. Biol. Chem. 253, 4451-4458 (1978)

10. S. Levi, S.J. Yewdall, P.M. Harrison, P. Santambriogo, A. Cozzi, E. Rovida, A. Albertini, P. Arosio, Evidence of $\mathrm{H}$ - and L-chains have co-operative roles in the iron-uptake mechanism of human ferritin. Biochem. J. 288, 591-596 (1992)

11. D. Boyd, C. Vecoli, D.M. Belcher, S.K. Jain, J.W. Drysdale, Structural and functional relationships of human ferritin $\mathrm{H}$ and $\mathrm{L}$ chains deduced from cDNA clones. J. Biol. Chem. 260, 11755-11761 (1985)

12. D.M. Lawson, A. Treffry, P.J. Artymiuk, P.M. Harrison, S.J. Yewdall, A. Luzzago, G. Cesareni, S. Levi, P. Arosio, Identification of the ferroxidase centre in ferritin. FEBS Lett. 254, 207-210 (1989)

13. E.R. Bauminger, P.M. Harrison, D. Hechel, I. Nowik, A. Treffry, Mössbauer spectroscopic investigation of structure-function relations in ferritins. Biochem. Biophys. Acta 1118, 48-58 (1991)

14. A. Treffry, J. Hirzmann, S.J. Yewdall, P.M. Harrison, Mechanism of catalysis of Fe(II) oxidation by ferritin H-chains. FEBS Lett. 302, 108-112 (1992)

15. P. Santambrogio, S. Levi, P. Arosio, L. Palagi, G. Vecchio, D.M. Lawson, S.J. Yewdall, P.J. Artymiuk, P.M. Harrison, R. Jappelli, G. Cesareni, Evidence that a salt bridge in the light chain contributes to the physical stability difference between heavy and light human ferritins. J. Biol. Chem. 267, 14077-14083 (1992)

16. R.R. Crichton, M. Charloteaux-Wauters, Iron transport and storage. Eur. J. Biochem. 164, 485-506 (1987)

17. M.J. Donlin, R.F. Frey, C. Putnam, J.K. Proctor, J.K. Bashkin, Analysis of iron in ferritin, the ironstorage protein: a general chemistry experiment. J. Chem. Educ. 75, 437-441 (1998)

18. A. Treffry, E.R. Bauminger, D. Hechel, N.W. Hodson, I. Nowik, S.J. Yewdall, P.M. Harrison, Defining the roles of the threefold channels in iron uptake, iron oxidation and iron-core formation in ferritin: a study aided by site-directed mutagenesis. Biochem. J. 296, 721-728 (1993)

19. A. Treffry, C. Hawkins, J.M. Williams, J.R. Guest, P.M. Harrison, Lability of iron at the dinuclear centres of ferritin studied by competition with four chelators. J. Biol. Inorg. Chem. 1, 49-60 (1996)

20. G.D. Watt, R.B. Frankel, G.C. Papaefthymiou, Reduction of mammalian ferritin. Proc. Natl. Acad. Sci. USA 82, 3640-3643 (1985)

21. J.P. Laulhère, A.M. Labouré, J.F. Briat, Photoreduction and incorporation of iron into ferritins. Biochem. J. 269, 79-84 (1990)

22. T.E. Graedel, M.L. Mandich, C.J. Weschler, Kinetic model studies of atmospheric droplet chemistry 2. Homogeneous transition metal chemistry in raindrops. J. Geophys. Res. 91, 5205-5221 (1986)

23. B.C. Faust, J. Hoigné, Photolysis of Fe(III)-hydroxy complexes as sources of OH radicals in clouds, fog and rain. Atmos. Environ. A 24, 79-89 (1990)

24. G.V. Buxton, W.P. Helman, A.B. Ross, Critical review of rate constants for reactions of hydrated electrons, hydrogen atoms and hydroxyl radicals in aqueous solution. J. Phys. Chem. Ref. Data. 17, 513-886 (1988)

25. V.V. Nikandrov, C.K. Grätzel, J.-E. Moser, M. Grätzel, Light induced redox reactions involving mammalian ferritin as photocatalyst. J. Photochem. Photobiol. B Biol. 41, 83-89 (1997)

26. M. Aubailly, R. Santus, S. Salmon, Ferrous ion release from ferritin by ultraviolet-A radiations. Photochem. Photobiol. 54, 769-773 (1991)

27. T. Paul, Effect of a prolonged superoxide flux on transferrin and ferritin. Arch. Biochem. Biophys. 382, 253-261 (2000)

28. D.W. Reif, J. Schubert, S.D. Aust, Iron release from ferritin and lipid peroxidation by radiolytically generated reducing radicals. Arch. Biochem. Biophys. 264, 238-243 (1988)

29. G.D. Watt, D. Jacobs, R.B. Frankel, Redox reactivity of bacterial and mammalian ferritin: is reductant entry into the ferritin interior a necessary step for iron release? Proc. Natl. Acad. Sci. USA 85, 7457-7461 (1988)

30. D.L. Jacobs, G.D. Watt, R.B. Frankel, G.C. Papaefthymiou, Redox reactions associated with iron release from mammalian ferritin. Biochemistry 28, 1650-1655 (1989) 